\title{
NOTAS SOBRE OS ESTUDOS LEGISLATIVOS DOS MUNICÍPIOS BRASILEIROS: AS DIFERENTES ABORDAGENS METODOLÓGICAS
}

Alan Rangel $^{1}$

\section{Resumo:}

O objetivo do seguinte paper busca sintetizar as principais contribuições sobre os trabalhos dos Estudos Legislativos no nível municipal, sobretudo em relação ao comportamento dos legisladores frente aos eleitores e ao Poder Executivo, e suas implicações locais. Assim, pretendemos alargar as discussões e nas considerações finais apontamos a lacuna de trabalhos comparativos.

Palavras-Chave: Legislativo Municipal; Cotidiano dos vereadores; Comportamento político

\section{Resumen:}

El objetivo del siguiente trabajo intenta resumir las principales aportaciones de la obra de los Estudios Legislativos en el ámbito municipal, sobre todo en relación con el comportamiento de los legisladores delante a los votantes y al Poder Ejecutivo, y sus consecuencias a nivel local. Por lo tanto, queremos ampliar el debate y las consideraciones finales destacamos la falta de estudios comparativos.

Palabras-clave: Legislativo Municipal; Cotidiano de los concejales; Comportamiento político.

\begin{abstract}
:
The objective of the following paper search summarize the main contributions and approaches on the work of Legislative Studies at the municipal level, particularly in relation to the behavior of legislators in relation the voters and the Executive - Power, and its local implications. So, we want to extend the discussions and the final considerations we have pointed out the lack of comparative studies.
\end{abstract}

Keywords: Municipal Legislature; Everyday of councillors; Political Behavior.

\footnotetext{
${ }^{1}$ Bacharel e Licenciado em Ciências Sociais e Mestrando em Ciências Sociais pela Universidade Federal da Bahia (UFBA). Financiamento do CNPQ.
} 


\section{INTRODUÇÃO}

A literatura mais recente sobre os Estudos Legislativos tem privilegiado as unidades nacionais e subnacionais; há, dessa forma, pouca ênfase nos municípios. Esta falta de atenção aos estudos sobre municípios é analisada por D’Avila Filho et al. (2010, p. 3):

\footnotetext{
Essa lacuna se deve às dificuldades dos vereadores em produzir legislação local significativa, diante dos constrangimentos impostos pelas Constituições Federais e Estaduais, restando pouca margem para a criatividade dos vereadores [...] Diante das razões que este autor expressa como causadoras da lacuna sobre os estudos do legislativo municipal, indica ele que [...]
}

Verificamos também uma atenção maior aos estudos sobre o Legislativo que ressoa mais ao sudeste brasileiro, principalmente nos estados de São Paulo, Rio de Janeiro e Minas Gerais. Silva (2010) fala de uma posição de perspectiva meramente cartográfica, se referindo aos "preconceitos regionais" dos cientistas políticos do eixo Rio - São Paulo. Nos trabalhos sobre as proposições dos legisladores no Brasil - afora da Câmara Federal tem-se como referência alguns estudos em São Paulo (ABRUCIO et al., 2001), Minas Gerais (ANASTASIA, 2001), Ceará (MORAES, 2001) e Rio de Janeiro (SANTOS, 2001), mas que versam sobre as Assembléias Estaduais, criando uma rede de conexões que buscam uma comparação paralela entre o Legislativo estadual e federal. Santos (2001) tem se apropriado da literatura norte-americana, a chamada teoria positiva da organização legislativa $^{2}$, que resgatou a ênfase nas instituições, como variável independente na compreensão da ação dos atores políticos na arena parlamentar, e resgatou também a teoria da escolha racional, onde agentes políticos atuam sempre para maximizar objetivos individuais. Muitas variáveis existentes na teoria positiva americana foram utilizadas para compreender a organização do Congresso Brasileiro, e teve rebatimento das pesquisas em torno dos governos estaduais. Nesse sentido, houve pouco espaço a nível municipal para pesquisas das referidas abordagens teóricas sobre os Estudos Legislativos.

Neste trabalho serão destacados dois estudos: Caetano ( 2005) e Silva (2011) que pesquisaram a relação Executivo - Legislativo em São Paulo, corroborando com a literatura dos estudos nacionais, utilizando variáveis como disciplina partidária e centralização decisória.

Além dessa introdução, mostraremos na seção a seguir que os fatores conjunturais específicos no âmbito local foram determinantes para que ocorresse um padrão de

\footnotetext{
2 São três as abordagens conceituais originárias do Neo - Institucionalismo de Escolha Racional para compreender o Congresso norte-americano: partidário, distributivista, e informacional. Em nosso trabalho nos referenciaremos à abordagem partidária e suas variáveis para o caso brasileiro.
} 
interação entre os poderes Executivo e Legislativo que combinasse governismo com distributivismo, ou em outras palavras, entre os interesses do Executivo e do Legislativo.

$\mathrm{Na}$ última seção, mostraremos trabalhos recentes (LOPEZ, 2004; RUGGIERO JUNIOR, 2005; FELISBINO, 2009; ALMEIDA e LOPEZ, 2011) que apontam a realidade local de alguns municípios considerando algumas variáveis empíricas utilizadas nos trabalhos sobre Congresso Brasileiro - centralização decisória; e Executivo com fortes poderes legislativos e capacidade de barganha - mas que salientam a importância da dinâmica cotidiana dos vereadores, que teriam dificuldades para legislar e fiscalizar, agindo com práticas que acentuam medidas assistencialistas. Estas últimas, como será mostrado, são habituais nestes estudos.

Nosso intuito, portanto, visa sintetizar as principais contribuições das pesquisas sobre Legislativos municipais, agregando as principais abordagens sobre o comportamento parlamentar.

\section{PERSPECTIVA PARTIDÁRIA}

A hegemonia teórica dos estudos sobre o Legislativo Federal brasileiro tem absorvido a perspectiva partidária da teoria norte-americana ${ }^{3}$, chamada de teoria positiva de organização legislativa, que tem origem no neo-Institucionalismo de Escolha Racional.

De acordo com Limongi (1994), o neo-institucionalismo apontou diversas incoerências epistemológicas na teoria do comportamentalismo (behaviorismo) e da teoria do pluralismo. $\mathrm{O}$ termo institucionalismo contrasta com o modelo individualista das teorias anteriores, pois coloca o primeiro como uma variável independente para as análises dos processos políticos. Segundo o autor, a denominação do novo institucionalismo visava distinguir do institucionalismo preponderante antes da II Guerra Mundial. Desta forma,

Para o novo institucionalismo da teoria da escolha racional, a esfera legislativa compreende um mundo em que os acordos são forjados entre agentes autônomos. Instituições são consideradas aqui como mecanismos imprescindíveis que diminuem os custos de transação ligados à conclusão dos acordos, de modo a propiciar aos atores os benefícios da troca (deference and reciprocity) sob a adoção de regras estáveis (arrangements) e resolução de problemas de ação coletiva (NASCIMENTO, 2010, p. 7).

\footnotetext{
${ }^{3}$ LIMONGI, 2006; FIGUEIREDO e LIMONGI, 1995; SANTOS, 2004; NETO, 2008.
} 
A vertente partidária situa o partido como ator principal na coordenação da arena parlamentar. Esta terceira geração de estudos das teorias positivas da organização legislativa foi impulsionada pelo trabalho introdutório de Cox e McCubbins. Em suas palavras,

\begin{abstract}
Influential researchers... have argued that structure - in particular the committee system - is key to understandingwhy decisions in Congress are not forever overturned byshifting majorities. We share this emphasis on structure butview as the key actors not the committees, but the parties.In ours view, congressional parties are a species oflegislative cartel. These cartels usurp the rule-makingpower of the House in order to endow theirs members with differential powers... Most of the cartel's efforts are centered on securing control of the legislative agenda for its members (COX e MCCUBBINS (1993), apud NASCIMENTO, 2010, p. 21).
\end{abstract}

Esta perspectiva coloca o partido como ator principal na coordenação da arena parlamentar. A formação das comissões seria entendida levando em conta a organização partidária da Casa. Neste cenário, o partido majoritário tem a prerrogativa de indicar líderes das comissões e sub-comissões, e também a capacidade organizativa de orientar as votações nominais nas políticas, bem como coordenar o processo legislativo. Existe, portanto, um cartel legislativo via partidos políticos.

O partido teria a capacidade de organizar as preferências heterogêneas para agir como uma unidade partidária através do líder do partido, este teria a importante função de reduzir os problemas de ação coletiva. Decerto, que

[...] a fim de garantir a troca de ganhos, legisladores devem cooperar, e os partidos, criar os meios necessários, de modo a confeccionar preferências afins entre os legisladores ou ao menos, coibir a busca de bens exclusivamente particularistas por parte de seus membros através de restrições institucionais [...] os Líderes de partido usam as ferramentas da organização congressional para estes fins [...] (NASCIMENTO, 2010, p. 24)

Estudos no Congresso Brasileiro, a partir da década de $90^{4}$, têm mostrado que os legisladores se comportam de acordo com a posição dos líderes partidários, corroborando com o modelo partidário americano ${ }^{5}$. Os estudos também mostram que a organização

\footnotetext{
${ }^{4}$ LIMONGI, 2006; FIGUEIREDO e LIMONGI, 1995, 2002; SANTOS, 2002, 2004; AMORIM NETO, 2008.

5 É importante não perder de vista as particularidades no caso brasileiro: "diferentemente da trajetória americana, a integração do Executivo à arena legislativa, mediante o uso de suas prerrogativas presidenciais de iniciativa legislativa e de atuação nesta arena, dilatou o campo analítico a partir do qual foram explorados os efeitos da organização interna sobre a produção legal. De forma predominante, as análises acerca da associação entre, de um lado, a distribuição de prerrogativa e direitos parlamentares, do recurso aos procedimentos legislativos e, de outro, o comportamento parlamentar partidariamente coordenado incluíram o papel interveniente do Executivo nesta arena”. (INÁCIO \& RENNÓ Org, 2009, p. 21)
} 
interna do Legislativo é predominante em relação à arena eleitoral, ou seja, as regras internas constrangem a atuação individual dos legisladores de influências exógenas.

\subsection{A perspectiva partidária e a especificidade brasileira no âmbito municipal}

Há dois trabalhos recentes que abordaram o cenário municipal, especificamente a capital paulista, corroborando com a perspectiva partidária levando em conta algumas variáveis adotadas nos estudos sobre o Congresso brasileiro, variáveis essas que são: centralização decisória, disciplina partidária, capacidade do Executivo em aprovar seus interesses.

Caetano (2005) procurou analisar a relação do Executivo e Legislativo, na grande São Paulo ${ }^{6}$, procurando compreender como se formam as maiorias parlamentares e a definição de agenda legislativa. $O$ autor identificou que o Executivo local, com a composição partidária majoritária, tem preponderância na formulação e aprovação da agenda dos trabalhos legislativos no plenário em relação aos projetos de leis. Assim, corrobora com o modelo partidário americano, acrescentando a particularidade que o Executivo brasileiro dispõe, a saber, elevado poder legislativo. $O$ autor dialoga com os estudiosos do poder local que afirmam que o presidencialismo brasileiro "faz com que os poderes Executivo e Legislativo sejam regidos por soberanias paralelas, que não regem incentivos à cooperação”. (CAETANO, 2005, p.107). Além desses possíveis problemas, os autores ainda infeririam que o sistema proporcional de lista aberta contribuiria para fragilizar os partidos brasileiros porque incentivaria ações individuais por parte dos atores políticos. Posto isto, essa concepção colocaria o Executivo com um poder homologatório, pois estaria:

[...] fazendo com que os parlamentares releguem a segundo plano a função legislativa e passem a ter como principal preocupação o controle dos instrumentos governativos que possibilitem a transferência de bens e serviços à sua clientela. Dessa maneira, a atividade legislativa exercida pelos parlamentares ficaria restrita a questões simbólicas, como a denominação de ruas, a distribuição de homenagens e o estabelecimento de datas comemorativas (CAETANO, 2005, p.107).

Mas esta visão, segundo Caetano, é problemática, mesmo a nível municipal. O autor tentará mostrar que a Câmara Municipal de São Paulo é altamente centralizada, corroborando com o modelo partidário. O prefeito da cidade paulista tem grande poder de 
interferir nos trabalhos legislativos, respaldado pelo Regimento Interno e Lei Orgânica do Município.

Analisando os anos de 2001 a 2004 na Câmara Municipal de São Paulo, o autor encontrou os seguintes dados: a) dos 218 projetos de leis do Executivo deliberados em plenário, no segundo turno pelos vereadores, só ocorreu apenas um veto. E, mesmo este caso isolado, teve o texto original modificado pelos vereadores e encaminhado de volta ao prefeito, que vetou a mudança, que posteriormente foi mantida pelo Legislativo; b) dos 573 projetos aprovados na Câmara e encaminhados para sansão do prefeito, 179 foram reprovados por este (cerca de 31,20\%); c) também dos 398 projetos que viraram leis, 217 $(55 \%)$ foram do Executivo, o que corrobora com a tese da forte influência do Executivo na instância da Câmara.

O autor fez um paralelo com o modelo distributivista ${ }^{7}$, que confere poder às Comissões e cria o principio da auto-seleção na composição das mesmas, na literatura americana. Ao contrário do Congresso Americano no qual uma proposição tramita em apenas uma comissão, no Brasil, de modo geral, os projetos precisam passar por pelo menos duas comissões, a de 'Constituição e Justiça' e de 'Finanças e Orçamento'; os projetos nas Câmaras brasileiras podem passar por diversas outras comissões a depender da matéria, porém a única comissão que pode barrar os projetos é a Comissão de Constituição e Justiça (CCJ). Assim “recebendo parecer favorável desta comissão, os projetos só não chegarão a plenário se forem rejeitados pela maioria das demais comissões de mérito em que tramitar." (CAETANO, 2005, p.114). Portanto, a capacidade de inviabilizar a tramitação dos projetos é muito reduzida no caso brasileiro, a exceção da CCJ. O autor apontou também que o que faz com que os projetos nas comissões tenham um comportamento padrão e tempo alterados são: a prerrogativa exclusiva do Executivo em solicitar regime de urgência, e o chamado "Congresso de Comissões".

Dos 218 projetos de leis do Executivo, em tramitação nas comissões, nos anos de 2001 a 2004, 119 tramitaram em regime de urgência. O que mostra a forte influência deste dispositivo. Já o Congresso de Comissões funcionaria como uma alternativa para reduzir o tempo de tramitação até chegar ao plenário: "é um conjunto de todas as comissões designadas, em que é elaborado um único parecer, assinado por todos os parlamentares pertencentes às comissões.” (CAETANO, 2005, p.115).

\footnotetext{
${ }^{7}$ Um dos modelos norte-americano da Teoria positiva da Organização Legislativa, que de modo geral, tem como ponto de partida a premissa de que os congressistas americanos buscariam em primeira instância a reeleição e, portanto, seu interesse maior é na alocação de recursos para seus redutos ou bases eleitorais. (NASCIMENTO, 2010)
} 
Em relação à formação da maioria na Câmara de São Paulo, Caetano pressupõe a hipótese de que um comportamento disciplinado das bancadas facilitaria a negociação com o Executivo, de modo mais eficiente do que se fosse realizado individualmente, seguindo, desta forma, o modelo partidário. Esse padrão foi verificado pelo autor: o PT, partido do governo durante o período estudado, ocupou a Comissão Executivapor quatro anos; além disso, a totalidade dos membros da Comissão era aliada à base do governo. Ainda, a presidência da 'Comissão de Constituição e Justiça' e 'Finanças e Orçamento', foi ocupada pelos membros da coalizão governista. E mais: das 28 presidências de todas as comissões durante os quatro anos, a oposição somente ocupou quatro vezes este posto.

Nas considerações, o autor reforça, portanto, a elevada capacidade de coordenação dos trabalhos legislativos pelos lideres dos partidos, em especial do líder do governo e mesa diretora. Também demonstrou a capacidade do governo de aprovar seus interesses na Câmara, o que comprova a capacidade do Executivo de sobrepor-se ao Legislativo, inclusive compondo maiorias na Casa. Assim, Caetano termina se contrapondo mais uma vez ao modelo distributivista, enaltecendo o modelo partidário, muito apreciado nos estudos do Legislativo Federal, principalmente por Limongi e Figueiredo. Para ele, ainda há, nos estudos acadêmicos sobre Legislativo, um olhar "folclórico e pitoresco" sobre o município. Em suas próprias palavras:

\footnotetext{
Essa é uma descoberta particularmente interessante, uma vez que a literatura especializada carece de estudos sobre a esfera local. Além disso, os trabalhos dos executivos locais e das câmaras municipais são costumeiramente relatados pela mídia como caóticos e desordenados. Redunda no senso comum a idéia de que as atividades dos vereadores e do Parlamento se restringem à aprovação de títulos, datas comemorativas e nomes de rua, fazendo do prefeito um refém dessa postura descompromissada com os problemas da cidade. A análise do caso paulistano, longe de esgotar o assunto, pretende lançar um foco de luz sobre esse debate. A Câmara Municipal de São Paulo não é um mero poder homologador de nomes de ruas e datas comemorativas. Uma importante agenda de projetos, orientada para a cidade, é debatida e aprovada no parlamento paulistano (CAETANO, 2005, p. 125).
}

Silva (2011), ao estudar a capital paulista, também mostrou que as apresentações dos projetos de leis pelos vereadores possuíam uma característica mais centrada numa distribuição mais geral a todo município e não a bases paroquiais. Portanto, se comprovaria, segundo ele, a inexistência da hipótese distributivista. O referido estudo concentrou-se nos governos de Marta Suplicy (2001-2004) e de José Serra/ Kassab (20052008), e também analisou os dados eleitorais das eleições de 2000 e 2004. 
Esse autor utiliza alguns conceitos da ciência política norte-americana, tais como o pork barrel que, em resumo, significa uma política voltada para agradar determinadas zonas geográficas onde geralmente estão situados os eleitores que premiaram os políticos. Portanto, uma medida localizada intencionalmente na espera de retornos eleitoreiros. O pork barrel estaria circunscrito com a hipótese da conexão eleitoral no comportamento dos legisladores na atuação das Câmaras. O autor mostrou empiricamente que os votos que os vereadores receberam nos dois anos de competição eleitoral - 2000 e 2004 - tem caráter mais disperso do que concentrado, pois a elevada competição eleitoral existente no município de São Paulo impede que os candidatos se focalizem somente numa região especifica. Foi identificado também na pesquisa que vereadores que tiveram votos mais concentrados apresentaram projetos de leis dos tipos geral e seccional. Mesmo resultado encontrado para os vereadores que receberam votos dispersos. Outra contribuição dada por Silva é ter identificado que os parlamentares que tiveram votação concentrada dominante, atuaram menos em termos de apresentação de projetos de leis do que aqueles que receberam votação de modo disperso ou compartilhado: nas duas legislaturas, $13^{\circ}$ e $14^{\circ}$ respectivamente, $24,5 \%$ e $38,5 \%$ foram a percentagem dos vereadores com voto concentrado que apresentaram projetos; e 45,7\% e 54,69\% dos legisladores com voto disperso. Também, os vereadores que mais apresentaram projetos de leis, com conteúdo dito irrelevantes ${ }^{8}$ foram os que tiveram votação concentrada nas duas eleições.

Ademais, sinaliza que não há evidências reais que coincidam sistemas eleitorais com voto pessoal e políticas paroquiais. Outra assertiva que o autor propõe, baseado no trabalho de Lemos (2001):

\footnotetext{
O vereador sendo racional não precisa focar em políticas para a sua constituency, pois os efeitos de uma política de cunho geral serão sentidos pelo seu eleitor. Deste modo, o eleitor racional de Downs (1999) que apesar preferir um benefício que o atinja diretamente, é capaz de identificar as melhoras na sua vida como um todo. Por exemplo, um eleitor que mora na zona sul pode se sentir satisfeito e beneficiado por um museu aberto na zona central da cidade (SILVA, 2011, p. 17).
}

Por fim, o autor finaliza apontando que a conexão eleitoral em São Paulo é residual no comportamento dos legisladores, pelo menos no que concerne aos projetos de leis,

\footnotetext{
8 “Apesar de parte da literatura e do senso comum considerar nomeação de logradouros como apenas uma homenagem este artigo discorda deste argumento. Afirmo que apesar de possuir um caráter simbólico e de homenagem dar nome a uma rua leva benefícios aos habitantes da mesma como, por exemplo, o morador passa a poder utilizar o endereço de sua residência no processo de abertura de conta bancária. Além de possibilitar ao Estado uma maior eficiência na taxação e coleta de impostos daquela rua, uma vez que as correspondências passam a ser entregues na moradia do contribuinte. Contudo, considero que renomeações não possuem tal efeito e, portando, elas que devem ser consideradas "inúteis" nos termos da Transparência Brasil (2008)" (SILVA, 2011, p. 14).
} 
contrariamente a uma literatura que associa representação proporcional de lista aberta, no âmbito municipal, com comportamento paroquial'. O que predominaria é um comportamento municipal.

\section{FATORES CONJUNTURAIS : ENTRE O GOVERNISMO $^{10}$ E O DISTRIBUTIVISMO ${ }^{11}$}

Nesta seção mostraremos dois trabalhos que relativizam o poder do Executivo frente ao Legislativo, mostrando que a conjuntura política sinalizará a relação de ambos os Poderes, num continuum entre governismo e distributivismo, este último proporcionando aos legisladores, prioritariamente, obter recursos para atingir suas bases eleitorais.

Pralon e Ferreira (1998) focaram suas análises na centralidade da Câmara Municipal de São Paulo, de 1989 (governo de Luíza Erundina) a 1993 (primeiro mandato do exprefeito Paulo Maluf), sobretudo no processo decisório, procurando compreender o grau de independência da Câmara em relação ao Executivo. Apontam que em cada gestão, os fatores conjunturais criam condições peculiares que podem explicar a fraqueza ou fortalecimento da Câmara. Um dos achados das autoras é de que a ação do Executivo, ou melhor, a forma de relacionamento deste com a Câmara, no início do mandato, é que poderá determinar o grau de conflitividade de ambos.

As autoras procuraram identificar os fatores estruturais "positivos" que atribuíram às Câmaras, de modo geral, uma centralidade no processo de decisão, após a Constituição de 1988. Alguns fatores estruturais, tais como: a) proximidade dos vereadores com os eleitores, geográfica e de competência, este se referindo ao impacto que a Câmara produz na vida cotidiana dos cidadãos, tais como transporte, saneamento etc. Essa proximidade do Legislativo com a população confere uma grande visibilidade por parte daquele que se expõe todo momento à opinião pública, incluindo a mídia. Esse cenário tende a ser bastante útil para a oposição que se aproveitaria desta visibilidade para tomar uma postura a favor de um debate público; e b) o prefeito para governar precisa de um forte apoio do Legislativo para aprovar suas políticas.

Há também aquilo que as autoras chamaram de fatores estruturais "negativos", são eles: a) a opção do governo para iniciar seu mandato com uma "coalizão fisiológica de

\footnotetext{
${ }^{9}$ Essa literatura se coaduna com a perspectiva teórica do modelo Distributivista norte-americano (MAINWARING, 2001; AMES, 2003).

${ }^{10}$ Governismo é a capacidade do Executivo de orientar os trabalhos legislativos (PRALON e FERREIRA, 1998).

11 Derivação do modelo Distributivista explicado brevemente na nota 7.
} 
governo" (CFG) ${ }^{12}$, que é traduzido pela distribuição de cargos e recursos aos partidos e seus parlamentares; b) a chamada "negociação pontual" (NP) ${ }^{13}$, onde os projetos são negociados pontualmente com os parlamentares, o que pode gerar vantagens para os vereadores, tais como obtenção de recursos para alocar aos seus eleitores, às suas bases etc. Assim, os parlamentares podem optar pelo governismo ou por ações estratégicas individuais.

No que tange a participação dos partidos políticos na Câmara paulista, as autoras os tratam como pouco incipientes a nível municipal. Os vereadores têm a preferência por optar em apoiar o governo em todo o mandato ou em políticas pontuais. Mas, seria mais eficaz para a sua reeleição optar pelo governismo, pois desta forma, o vereador terá acesso a certos recursos, e também contatos com grupos econômicos, que podem vir a apoiar sua eleição. Portanto, o que o vereador leva em conta é o atendimento a demandas específicas e particulares, é isso que garante sucesso em seu mandato. Ainda considerando os fatores negativos, outra deficiência dos vereadores frente ao prefeitoé a baixa capacidade técnica dos legisladores nas comissões.

$\mathrm{Na}$ CFG, o Legislativo perderia importância por abrir mãos de suas funções de controlar o Executivo e vetar projetos, portanto, a autonomia da Câmara vê-se enfraquecida frente ao Poder Executivo. Mesmo essa coalizão está sujeita a oscilações, pois,

É necessário, por parte, do governo ou de seu líder na Câmara, um trabalho constante de arregimentação dos vereadores simpáticos ao Governo. Para entender melhor este ponto, vale observar que a distribuição de Administrações Regionais não é a única moeda no acordo que envolve prefeitura e vereadores na construção de uma maioria e apoio ao Executivo dentro do Parlamento. Uma outra moeda importante são as ações da prefeitura, ou seja, as obras que ela realiza ao longo da gestão. Grande parte dos vereadores tem uma base eleitoral regionalizada na capital; ou seja, há uma espécie de "distritalização", na prática, no pleito eleitoral (PRALON e FERREIRA, 1998, p.83).

Outro ponto que enfraquece a CFG é a repercussão de projetos polêmicos adotadas pelo Executivo, que aumentaria a visibilidade através da mídia local e da opinião pública. Alguns vereadores podem optar por não participar da aprovação de determinados projetos, pois pode ver seu nome junto à sociedade de forma negativa, mesmo que seja contrária a orientação de seus partidos. Assim, “os fatos indicam que não é tão fácil, no âmbito municipal, a construção de uma maioria realmente estável de sustentação do

12 Termo também utilizado por Andrade (1998), da mesma obra.

13 Termo também utilizado por Andrade (1998), da mesma obra. 
governo no Parlamento. A Câmara tende, portanto, a reservar para si um certo grau de autonomia.” (PRALON e FERREIRA, 1998, p. 85)

As autoras concluem que importa aos vereadores privilegiar ações individuais para alcançarem a realização de um mandato positivo que lhes proporcionem reeleição ou alcance de outros cargos. Em certo sentido, tanto na CFG e na NP, a Câmara resguarda certa autonomia e centralidade no processo decisório, explicados pelos "fatores estruturais positivos".

O segundo trabalho a orientar as análises expostas nessa seção é o de Couto (1998), que buscou compreender possibilidades de interação entre o Executivo e Legislativo no cenário de presidencialismo brasileiro, e posteriormente analisando empiricamente o cenário municipal paulista, nos governos de Mario Covas, Jânio Quadros e especialmente Luiza Erundina (1988-1992), observando os diferentes padrões de relacionamento entre os Poderes.

O autor classificou padrões de interação entre os Poderes Legislativo e Executivo baseado em cinco variáveis: estratégia, que pode ser cooperativa ou conflitiva (competitiva); modalidade, podendo ser estável (coalizão/oposição rígida) ou instável (negociações pontuais); moeda de troca (caráter), que pode ser programática ou alocativa/fisiológica; cenários, majoritário ou consensual; e qualidade da decisão. Todos os efeitos destas variáveis, têm impacto na capacidade decisória, na capacidade de produzir outputs (fluxo de decisões políticas, responsividade frente às demandas da sociedade) do sistema político.

O que importa para nossa exposição é mostrar quais os padrões existentes primeiro no âmbito federal e depois no municipal. No primeiro, o fenômeno marcante é a Coalizão Fisiológica de Governo (CFG), caracterizado pelo presidencialismo peculiar existente no cenário brasileiro. Antes da Constituição de 1988, o Legislativo era esvaziado das decisões políticas, tinha frágil poder frente ao Executivo, que utiliza sem restrição o decreto-lei e o decurso de prazo (para projetos de leis). Neste sentido, o Legislativo brasileiro não criava muitas resistências ao presidente, pois legitimavam o regime além de estar envolvidos com práticas de fisiologismo e clientelismo. (COUTO, 1998)

Após a promulgação da nova Constituição, o Legislativo ganharia mais poder, passando a ter mais competência de decisão, como, por exemplo, na Lei Orçamentária, com a extinção do decurso de prazo e do decreto-lei. Por outro lado, as Medidas Provisórias deram razoável poder ao Executivo Federal neste novo período. Porém, 
O arcabouço institucional vigente não é propício a uma atuação dos parlamentares com respeito ao processo governativo, pois não proporciona incentivos a uma prática cooperativa entre os Poderes e nem à preocupação com as dimensões republicana e técnica da ação governamental. A fragilidade organizacional dos partidos associada à externalidade dos Poderes contribui para uma atuação atomizada dos legisladores, orientada, sobretudo, para o atendimento de demandas localizadas e particulares de suas bases políticoeleitorais, desvinculando a função de representantes mais imediatos dessas bases (brokers) daquela de co-governantes (COUTO, 1998, p. 59).

Desta forma, o autor ainda reforça que os legisladores não estariam preocupados com um projeto político nacional, mas sim em um projeto individual, que é a sua própria carreira política, costurando relações com suas bases eleitorais. A CFG seria a opção mais racional por parte do Executivo para aplicar o programa político de governo e atender propostas legislativas dos congressistas, sem que isso possa, logicamente, prejudicar as ações do chefe do Executivo para o país, o que poderia gerar paralisia decisória.

O caso paulista mostrou algumas peculiaridades interessantes sobre os padrões de interação entre os Poderes. O autor analisou três governos municipais, de 1982 até 1992, o primeiro foi Mario Covas (1982 a 1985) indicado por voto indireto; o segundo foi Jânio Quadros (1986 a 1988) e Luiza Erundina (1988-1992). O governo de Mario Covas foi marcado por uma maioria parlamentar estável, que não dificultou a realização de seus objetivos. Em determinados momentos teve de buscarapoio da oposição através de negociações pontuais, pois seu partido, o PMDB, possuía algumas dissidências. Mas nada que prejudicasse a cooperação.

No governo de Jânio Quadros, o Executivo cedeu as Administrações Regionais (ARs) em São Paulo aos vereadores, em troca de apoio parlamentar. Estes loteamentos favoreciam os vereadores para direcionarem recursos em suas prioridades políticoeleitorais, em uma relação de cooptação clientelista com suas bases. Com isso, os vereadores cooperavam com o Executivo na aprovação de seus objetivos programáticos. Portanto, em seu governo houve o estabelecimento da CFG. A coalizão foi formada individualmente com os parlamentares, a exceção de parte do PMDB e do PT, estes fizeram oposição rígida ao governo.

$\mathrm{Na}$ gestão de Luíza Erundina, o autor identificou características não vistas anteriormente nos padrões de relação entre os Poderes, e também destoou com relação ao padrão dominante no nível federal. $\mathrm{O}$ autor centrou maiores esforços nesta gestão, e iremos detalhar de forma cuidadosa a peculiaridade deste período.

Couto apontou que no primeiro momento a prefeita de São Paulo, do PT, optou pela estratégia conflitiva. Procurou explicar esta estratégia inicial pelas características do PT: 
originário de grupos de esquerda contra a ditadura; pouco afeita aos princípios das regras de representação democrática representativa e negando a democracia formal/procedimental por outra mais substantiva. Todas essas características criariam uma atmosfera de total oposição aos partidos oriundos da ditadura e contra os preceitos referidos à democracia-popular. Neste sentido, os petistas que chegavam ao governo da capital paulista buscavam apoio dos movimentos sociais, de bairros, conselhos e o apoio popular. Contudo, “a 'utopia participatória' consubstanciada nos ideais de democracia direta, associada 'à utopia presidencialista' do autoritarismo executivista, logo deu mostras de sua debilidade" (COUTO, 1998, p. 64). Então, com a pressão da sociedade pela responsabilidade de governar, o Executivo teve que ser mais flexível em relação às suas características identitárias originais, e transitar da 'ética da convicção para a ética da responsabilidade', como o próprio autor descreve.

Desta forma, a mudança de postura da gestão da prefeita e do PT incorporou ações que antes seriam deprezíveis para os partidários petistas, tais como a negociação política com os opositores, os legisladores. Assim, as práticas adotadas foram as negociações pontuais, programáticas e alocativas. Nos anos de 1990 a 1991, o autor identificou negociações baseadas na aprovação de emendas dos vereadores, que visavam atender as demandas locais, "procurando enquadrá-las dentro de um programa mais amplo de ação governamental, mas que informassem o processo decisório das necessidades mais localizadas; ou seja, realizou-se a barganha alocativa" (COUTO, 1998, p.65).

Por outro lado, a não-formação da CFG deu mais força à Câmara paulista, portanto concedendo mais centralidade e visibilidade no processo decisório, o que Pralon e Ferreira (1998) já haviam apontado.

Nas conclusões, o autor apontou que os interesses privados, por parte dos vereadores de São Paulo, foram sendo incorporados com os projetos governamentais, tido como interesses gerais, por parte do Executivo. Ou seja, não houve aquilo que o autor chama de "padrão patrimonial de interação entre os Poderes", como seria típico da tradição brasileira. Não houve, portanto, nestas experiências, uma preponderância de um Poder sobre o outro, mas um jogo de negociações. Por fim,

[...] O pequeno desvio proporcionando pela Barganha Alocativa, em relação ao universalismo e à coerência técnica ideais e absolutos de uma política programática fundada numa coalizão estável talvez seja o preço a se pagar pela democracia (COUTO, 1998, p. 69). 


\section{GOVERNISMO E O COTIDIANO DA POLÍTICA LOCAL}

Mostraremos nesta seção que a maioria dos trabalhos sobre o Legislativo municipal tem corroborado com os instrumentos analíticos utilizados pelos cientistas políticos brasileiros que acrescenta que arena parlamentar centraliza as decisões, e que o executivo não tem tido dificuldades para governar e aprovar suas políticas de governo. Por outro lado, estes mesmos estudos, que veremos adiante, mostra a peculiaridade que existe no contexto local: para além de apoiar o Executivo em seus objetivos, os vereadores tendem a voltar-se a práticas que visam beneficiar indivíduos ou grupos locais. Portanto, os autores colocam a importância do cotidiano para uma compreensão mais enriquecedora do comportamento dos vereadores.

Ruggiero Junior (2005) realizou uma pesquisa na cidade de Araraquara, São Paulo, visando compreender a atuação dos vereadores no processo Legislativo em momentos distintos (1997-2000 e 2001-2004), na relação com o Executivo, no que tange aos projetos de leis ordinárias. Sua conclusão é de que houve um aumento significativo do poder e controle do Executivo na agenda legislativa nos dois períodos - o primeiro governado pelo PPB e o segundo pelo PT. Houve ampliação da submissão do Legislativo ao Executivo, não ocorrendo, portanto, grandes obstáculos aos interesses do Executivo. $\mathrm{O}$ autor observou uma oposição frágil nos dois períodos. Houve um padrão de organização partidária bastante enfraquecida, a exceção do PT. Isso ocorreu devido à elevada taxa de migração partidária e a programas pouco significativos na plataforma política dos partidos. O que foi visto no segundo período, portanto, foi um aumento de ações particularistas. Foi identificado, por parte dos vereadores, proposições de leis "pouco relevantes".

Em uma das entrevistas que o autor realizou, o longo depoimento mostra o informalismo presente na Câmara para com os eleitores.

\footnotetext{
Dou atendimento às pessoas aqui no meu gabinete todos os dias, de manhã e de tarde. Tenho uma rotina de visita nos bairros, nas comunidades e nas igrejas evangélicas, esse é meu dia a dia. A verdadeira e principal função do vereador é fiscalizar o Executivo. Hoje nem só isso, porque as pessoas tem dificuldade, então eu, homem público, auxilio com diálogo, encaminhando e em passar uma esperança para elas. Estão difíceis as coisas, o desemprego, falta de dinheiro às vezes até pra comer, e as pessoas ficam desesperadas; então você tem que auxiliar. [...] é um bom atendimento que a gente dá aqui no gabinete, com respeito às pessoas, não enganando ninguém, não pregando sonhos impossíveis e falando a verdade. Então, este trabalho repercute nas pessoas e elas levam pro seus bairros. Lá comentam 'no gabinete de fulano de tal, eu fui e ele me atendeu assim e assim' e dali a pouco começam a aparecer outros, passaram estas informações para as pessoas (RUGGIERO JUNIOR, 2005, p. 174).
} 
Ao realizar entrevista com outros vereadores, o autor identificou em seus depoimentos a fragilidade que os parlamentares possuem para agirem de maneira formal/institucional no escopo da Câmara de Araraquara. Desta forma:

\begin{abstract}
Ficou demonstrado que os vereadores adotam diferentes posturas de trabalho. Concordam que a restrição que sofrem em alguns temas na produção legal, faz com que tenham menos espaços nos projetos de leis diante das propostas do Executivo. Muitos estreitam o contato com a sociedade, bairros e segmentos específicos, mas neste comportamento alguns partem para uma ação negativa do vereador, "despachante" e clientelista. Há os que não são claramente assistencialistas, mas contemplam grupos e interesses particulares com projetos específicos [...] (RUGGIERO JUNIOR, 2005, p.182).
\end{abstract}

A fiscalização ao Executivo também é muito precária, pois os poderes dados aos prefeitos, respaldados pelo Regimento e Constituição, fragiliza uma ação mais responsável e efetiva do Legislativo. Nos dois períodos analisados, as Comissões tiveram sempre também a hegemonia da base governista.

Felisbino (2009) centrou seu estudo no município de Mogi-Mirim (1960-1963 e 1997-2000), São Paulo, na relação Executivo-Legislativo. A metodologia do trabalho foi de entrevista com vereadores e análises dos projetos de leis ordinárias oriundas dos dois Poderes. Chegou também à conclusão de que a Casa Legislativa tem sido subordinada ao Poder Executivo devido a recursos após a redemocratização, regulamentado pela Constituição Federal e o próprio Regimento Interno da Casa.

O autor analisou o período de 1960 a 1963, e mostrou que os vereadores não dependiam da agenda do chefe do Executivo para apresentação de proposições de leis ordinárias. Ou seja, havia uma pauta compartilhada. Nos de 1962 e 1963 mais de 50\% das propostas foram oriundas do Legislativo. Já no período entre 1997 a 2000, o Executivo já controlava os trabalhos na Câmara, e essa cooperava com as preferências daquele. Os projetos do prefeito, em sua maioria, foram aprovados em plenário; este cenário já retratara o perfil do governismo, onde os legisladores apoiariam o chefe do Executivo para "ter acesso a recursos indispensáveis para a atividade cotidiana e sobrevivência política junto ao eleitorado, do vereador. Os vereadores necessitam de recursos controlados pelo prefeito [...] (FELISBINO, 2009, p.31).

Sobre a atuação individual do vereador, o autor, ao realizar observações diárias no cotidiano dos vereadores, percebeu que eles dedicavam-se maior parte de seu tempo para atendimento direto aos eleitores, com demandas em sua maioria particulares, tais como consulta médica, emprego, cestas básicas, remédios etc. Outros dispositivos parlamentares, 
tais como moções, requerimentos e indicações estão no rol de estratégias que a vereança utilizara para uma ação individualizada que independe do partido que esteja afiliado. O autor reitera a importância do dispositivo Indicação ${ }^{14}$ para o mandato do vereador, pois “com a promulgação da Constituição Federal de 1988, somente ao chefe do Executivo é permitido aprovar medidas que geram gastos" (FELISBINO, 2009, p. 34). Portanto, a Indicação é uma das válvulas de escape que a vereança utiliza para aproximar-se de seus eleitores. É importante também ter bom relacionamento com o prefeito para que as demandas de caráter localista de atendimento a grupos específicos, sejam atendidas pelo Poder Executivo. Estando na situação, as chances serão maiores. Assim,

[...] É importante lembrar que a iniciativa dos projetos de leis que possam atender os serviços de importância imediata cabe ao chefe do Executivo. Os vereadores não podem criar gastos e diminuir receitas do município. Esse limite constitui um obstáculo para a iniciativa dos vereadores ao encaminharem determinados projetos (FELISBINO, 2009, p. 41).

Nas considerações finais, Felisbino reitera a capacidade do Executivo municipal principalmente no período da pós-redemocratização - de prerrogativas institucionais, e de controlar a agenda do Legislativo, da Mesa Diretora e nas Comissões especiais e permanentes. Mas concluiu também que a Câmara Municipal ganhou mais importância quanto ao potencial de dividir responsabilidades na administração municipal.

Lopez (2004) estudou o cotidiano do vereador em uma cidade do Rio Janeiro, Araruama na perspectiva de uma antropologia política (incluindo valores culturais e representações sociais). Retratou que atividades informais dos vereadores com a população é uma tônica presente neste município, pois as relações de assistencialismo com as suas bases, as trocas de favores, as relações face a face, seja no gabinete ou nos bairros, são comuns. Identificou que o Executivo é um ator muito decisivo na relação com os vereadores devido aos dispositivos internos que os favorece. Estar na base do prefeito, votar favoravelmente aos interesses do Executivo, é ter a certeza de que poderá contar com recursos importantes da prefeitura que certamente irá favorecer o vereador no sentido de alocar recursos materiais para suas bases. Assim, em Araruama, há uma forte preponderância e domínio do Executivo em relação ao Legislativo, não só referente às votações favoráveis àquele, como também a falta de fiscalização das contas da prefeitura.

Sobre a esfera municipal, Lopez (2004, p.156) afirma:

\footnotetext{
${ }^{14}$ Dois trabalhos recentes retratam a importância dos Projetos de Indicações no mandato dos vereadores. Ver D’Avila Filho, Jorge e Lima (2010) e Rangel (2013).
} 
[...] $\mathrm{Na}$ esfera política municipal, notadamente na relação entre os agentes políticos e os eleitores, o mundo público das leis impessoais e universais é constantemente confrontado com a necessidade de burlá-lo para atender às demandas do universo privado dos parentes, dos amigos, dos apadrinhados, dos aliados.

O autor cita que as indicações e moções estão entre os dispositivos legislativos mais utilizados pelos vereadores. As moções tem por características renovar e celebrar relações de amizades ou alianças políticas com membros da administração e futuros eleitores. As indicações têm um caráter sempre localista, ou seja, busca resolver problemas específicos tais como: calçamento de ruas ou iluminação em alguma via. Além disso, as indicações são sempre direcionadas aos locais onde o vereador obteve maior número de votos, e aí se concentraria a atuação mais efetiva do político. Paralelamente, os eleitores sentem-se representados por estes atores políticos que agem em sua comunidade, bairro ou localidade. O autor chamou esta representação de espacial. (Lopes, 2004)

As relações de parentesco para cargos na Câmara de Araruama é habitual. O parentesco auxilia os vereadores na captura de votos nas campanhas eleitorais, no atendimento aos eleitores nos gabinetes e nas localidades. Os assessores estariam dentro do espectro de confiança dos vereadores, evitando assim as traições políticas. Fazem também um papel de cabo eleitoral.

Lopez, neste mesmo estudo mostra através de algumas entrevistas, como o vereador realmente parece ser visto pelos representados. Os vereadores, de modo geral, descrevem que eles não são vistos como aquele que tem as funções de fiscalizar o Executivo ou que vai criar novas leis ou regras; ele é visto como alguém que deve resolver problemas pessoais como: passagens de ônibus, consultas médicas, empregos etc. De forma constante, o autor mostra que é a capacidade de atendimentos às bases que determina o futuro positivo ou negativo do vereador na carreira política. O prestígio do vereador aumenta na medida em que atende aos seus eleitores. Esta idéia é corroborada sempre com as entrevistas. "Fora do assistencialismo não há salvação" (LOPEZ, 2004, p. 166).

E, por fim, o autor realça que o que foi encontrado em Araruama reforça o embricamento que existe entre as novas instituições burocráticas democráticas e antigas práticas de intermediação de trocas sociais, "a observação empírica ressalta que as relações clientelísticas não antagonizam o desenvolvimento das instituições burocráticas ou as ideologias cívicas" (LOPEZ, 2004, p. 174). 
Almeida e Lopez $(2011)^{15}$ analisaram a percepção política dos vereadores e sua interação com Executivo e eleitores em quatro cidades de Minas Gerais, nos meses de julho e agosto de 2010, através de entrevistas com os próprios vereadores. Mostraram que no âmbito local a representação política é baseada, em larga escala, no atendimento às bases eleitorais, sobretudo a nível informal, como já vimos anteriormente no trabalho de Lopez (2004) e em algumas entrevistas do trabalho de Ruggiero Junior. E essas práticas interagem com os conteúdos formais. No trabalho de campo, os autores perguntaram aos vereadores quais as práticas que os eleitores mais prefeririam: se seria uma função de caráter institucional ou uma prestação de serviços. Dos 43 vereadores entrevistados, 62,8\% veem a percepção da prestação de contas como mais relevante na ótica dos representados. Outra pergunta endereçada aos vereadores foi referente à percepção deles sobre qual tipo de mandato devem, prioritariamente, exercer: se um mandato imperativo (age de acordo com os interesses diretos de seus eleitores) ou o mandato virtual (age de forma autônoma frente a sociedade). As respostas mostraram que quase $60 \%$ deles achavam que os legisladores devem exercer a função virtual de mandato. $O$ que cria certo paradoxo com o item da relevância política nas prestações de serviços, apontada anteriormente.

Quanto ao cotidiano dos vereadores, os autores esboçaram perguntas referentes, sobretudo, ao modo como eles se comunicam em seu mandato com os eleitores. Selecionamos a pergunta que discorre quanto à forma de atendimento aos eleitores, nas quatro cidades mineiras: 43,2\% dos vereadores usam recursos próprios para atender à população; $35,1 \%$ aciona a prefeitura; $4 \%$ utiliza ambos, recursos próprios e a prefeitura, e $16,2 \%$ não costuma atender aos pedidos. Outra pergunta feita foi sobre qual seria, em tese, a principal atividade cotidiana do vereador, classificados em institucional (dedica-se à atividades do tipo legislar e fiscalizar); assistencialista (atendimento aos eleitores principalmente por recursos próprios) e mediadores ( busca os recursos da prefeitura para atender às bases). Os resultados mostraram que 40\% dos entrevistados percebem a categoria institucional como a mais importante, seguida do assistencialista com 37,8\% e 21,6\% o de mediador. Portanto, as práticas institucionais e assistencialistas rivalizam na atividade cotidiana dos vereadores.

Os autores também buscaram compreender como ocorre a produção legislativa nos municípios analisados, sobretudo os projetos de leis, no ano de 2009. Os resultados foram os seguintes: de 311 projetos apresentados, $72 \%$ são oriundas do prefeito e $28 \%$ dos vereadores.

\footnotetext{
15 Ambos seguindo uma linha da Antropologia Política.
} 
Houve a sinalização de que há também uma predominância do executivo frente ao legislativo nestes municípios, acompanhando os trabalhos de Ruggiero Junior e Lopez. $85 \%$ dos entrevistados reconhece que o apoio à prefeitura cria maiores possibilidades de obter recursos necessários para atender aos eleitores, principalmente via indicações. Há, claramente, a tendência ao governismo. Outra questão analisada foi procurar compreender a importância dos partidos a nível municipal. As entrevistas apontaram que os partidos políticos são confundidos com grupos políticos locais, com demonstra a citação abaixo,

[...] o devido entendimento da relação entre o Poder Executivo e Legislativo pode prescindir da análise partidária, mas não de como se relacionam os grupos políticos locais. São esses que retratam a unidade social e política em torno da qual se formam e estruturam as disputas de poder local. As redes de aliança, ou atores em competição, se enfeixam em grupos políticos (ALMEIDA e LOPEZ, 2011, p.30).

Por fim, Almeida e Lopez sinalizam que a representação dos vereadores prestaria a uma forma de auxiliar ao Poder Executivo, pois

\begin{abstract}
Ao mediar as demandas diretas do eleitorado, e serem atores que incorporam como uma de suas atribuições - informais - relevantes estar em contato permanente com a população, eles estão informados o suficiente sobre os problemas, as demandas e as necessidades, coletivas ou particulares, em cada ponto do município. É como se o vasto número de indicações legislativas dirigidas ao Executivo, combinado com igual número de "pleitos" informais feitos diretamente à administração, assumissem papel informativo crucial para as secretarias de governo (ALMEIDA e LOPEZ, 2011, p. 34).
\end{abstract}

\title{
5. CONSIDERAÇÕES FINAIS
}

O balanço dos trabalhos realizados sobre o Legislativo no nível municipal buscou apontar algumas semelhanças a partir de abordagens do campo de estudos do legislativo orientado, no caso brasileiro, pelas pesquisas acerca do Congresso Nacional. As pesquisas também retrataram a peculiaridade existente no âmbito local e os efeitos advindos das práticas dos vereadores.

Porém, estudos comparativos ${ }^{16}$ de capitais e outros municípios em diferentes regiões do país, que não seja concentrado no eixo sul-sudeste, podem enriquecer mais os trabalhos sobre o comportamento dos vereadores para futuras discussões na área.

\footnotetext{
16 A exceção foi Kerbauy (2005) construiu um mapeamento mais amplo sobre os estudos municipais no Brasil, em todas as regiões, e recortou mais especificamente a sua análise empírica para os municípios de São Paulo (42 municípios) e Santa Catarina (19 municípios) - de 1996 a 2004 - usando categorias como população, eleitorado, distribuição de prefeitos e presidentes de Câmaras por faixa etária, escolaridade, partidos, relação do Executivo com oJudiciário e oLegislativo, formulação de políticas públicas, dentre outras.
} 
- Para Kerbauy (2005) há duas lógicas correntes, que coexistem hoje nos municípios, uma que mantém o tradicionalismo e outra que tende para a democracia formal:

O governo municipal vive hoje, em decorrência das novas regras sobre as relações intergovernamentais e das novas funções que deve exercer, um período de reconfiguração da arena decisória e dos processos de tomada de decisão, convivendo com duas lógicas distintas e contraditórias: (1) o tradicionalismo e as ações clientelistas que sempre caracterizaram o poder local e (2) os procedimentos universais que caracterizariam ações mais inovadoras das lideranças locais. (KERBAUY, 2005, p. 362)

Acreditamos, assim, que as pesquisas devem levar em consideração tal perspectiva ao orientarem suas análises.

\section{REFERÊNCIAS BIBLIOGRÁFICAS}

ABRUCIO, F. L.; TEIXEIRA, M. A. C.; COSTA, V. M. F. O Papel Institucional da Assembléia Legislativa Paulista: 1995 a 1998. In: SANTOS, F. O Poder Legislativo nos estados: diversidade e convergência Rio de Janeiro: FGV, 2001, cap. 6, p. 219-246.

ALMEIDA, A.; LOPEZ, F. Representação Política Local: padrões de atuação dos vereadores em quatro cidades mineiras. IPEA, Brasília, 1625, p. 1- 44, 2011.

AMES, B. Os Entraves à democracia no Brasil. Rio de Janeiro: Fundação Getúlio Vargas, 2003.

ANASTASIA, F. Transformando o Legislativo: A Experiência da Assembléia Legislativa de Minas Gerais. In: SANTOS, Fabiano. O Poder Legislativo nos estados: diversidade e convergência Rio de Janeiro: FGV, 2001, cap. 1, p. 23-81.

ANDRADE, R. de C. (org.). Processo decisório na Câmara dos Vereadores e na Assembléia Legislativa de São Paulo. In: Processo de governo no município e no estado: uma análise a partir de São Paulo. São Paulo: Editora USP, 1998, p. 15-40.

CAETANO, B. Executivo e Legislativo na esfera local. Novos Estudos Cebrap, n.71, março 2005, p. 101-125.

COUTO, C. G. Negociação, decisão e governo: padrões interativos na relação ExecutivoLegislativo e o caso paulistano. In: ANDRADE, R. de C. (org.). Processo de governo no município e no Estado. São Paulo: Editora da Universidade de São

Paulo, 1998. 
D’AVILA FILHO, P. M.; JORGE, V. L., LIMA, P. C. G. C. Produção Legislativa e Intermediação de Interesses na Câmara Municipal do Rio de Janeiro. In: VII Encontro da ABCP, Recife, Anais,Recife: ABCP, 2010, p. 2 -24.

FELISBINO, R. de A. Atores e práticas na relação executivo-legislativo municipal: o caso do município de Mogi-Mirim (SP) em dois contextos democráticos (1946-1964 e pós- 1988). Rev. OMNIA HUMANAS, v. 2, n. 1, p.27- 47, jan./ jun. 2009.

FERreirA, G.; PRALON, E. M. Centralidade na Câmara Municipal de São Paulo no Processo Decisório. In: ANDRADE, R. de C. (org). Processo de governo no município e no estado: uma análise a partir de São Paulo. São Paulo: Editora USP, 1998, p. 73-86.

FIGUEIREDO, A. C.; LIMONGI, F. Incentivos Eleitorais, Partidos e Política Orçamentária. DADOS - Revista de Ciências Sociais, Rio de Janeiro. Vol. 45, n 2, p. 303-344, 2002.

KERBAUY, M. T. M. As Câmaras Municipais Brasileiras: perfil de carreira e percepção sobre o processo decisório local. Opinião Pública, Campinas, v.2, p. 337-365, 2005.

INÁCIO, M. Estrutura e Funcionamento da Câmara dos Deputados. In: MELO, C. R.; SÁEZ, M. A. (Org.). A Democracia Brasileira: balanços e perspectivas para o século 21. Belo Horizonte, Editora UFMG, 2007

LIMONGI, F. O Novo Institucionalismo e os Estudos Legislativos: A Literatura Americana Recente. BIB - Boletim Informativo e Bibliográfico de Ciências Sociais, São Paulo, n. 55, 1994.

LIMONGI, F; FIGUEIREDO, A. Processo orçamentário e comportamento legislativo: emendas individuais, apoio ao Executivo e programas de governo. Dados - Revista de Ciências Sociais, v. 48, n. 4, p.737-776, dez. 2005.

LOPEZ, F. G. A política cotidiana dos vereadores e as relações entre executivo e legislativo em âmbito municipal: o caso do município de Araruama. Rev. Sociologia e Política, Curitiba, 22, 153-177, jun. 2004.

MAINWARING, Scott P.. Sistemas Partidários em Novas Democracias: o caso do Brasil. Tradução de Vera Pereira, Porto Alegre, Mercado Aberto, Rio de Janeiro, Editora FGV, 2001.

MORAES, F. A Dinâmica Legislativa da Assembléia do Estado do Ceará: 1995 a 1998. In: SANTOS, Fabiano. O Poder Legislativo nos estados: diversidade e convergência. Rio de Janeiro: FGV, 2001, cap. 5, p. 189-218 
NASCIMENTO, E. O. Modelos de organização legislativa. São Paulo: Revista Política Hoje, Vol. 382 19, n. 2, 2010.

RANGEL, A. B. Um estudo sobre a utilização dos Projetos de Indicações na Câmara Municipal de Salvador. In: III Fórum Brasileiro de Pós-Graduação em Ciência Política, 2013, Curitiba, GT: Estudos Legislativos, Curitiba, UFPR, p. 1-25.

RAUPP, F. M. Ensaio teórico sobre a presença do patrimonialismo no poder legislativo local. XV SEMEAD - Seminários em Administração. São Paulo: Programa de Pós -Graduação - FEA USP. ISSN 2177- 3866: 2012, p.1-16.

RUGGiero JUNIOR, N. A atuação do vereador na Câmara Municipal de Araraquara: processo legislativo em dois momentos. 2005, 233 f. (Dissertação em C.Sociais) - Centro de Educação em Ciências Humanas da Universidade Federal de São Carlos, São Carlos, 2005.

SANTOS, F. Partidos e comissões no presidencialismo de coalizão. Rio de Janeiro: DADOS, vol.45, n.2, p.237-264, 2002.

SANTOS, F. O poder legislativo no presidencialismo de coalizão. Belo Horizonte: Ed.UFMG; Rio de Janeiro: IUPERJ, 2004.

SILVA, Patrick. O pork barrel no Município de São Paulo: a produção legislativa dos vereadores paulistanos. Centro de Estudos da Metrópole (CEM), São Paulo, 2011, p. 1 25.

SILVA, C.D.P. A Lógica da Competição Política Municipal em “Cenários Oligárquicos". VII Encontro da ABCP, Recife, 2010, p. 2 -23. 